\section{Pavonia $\times$ rufula (Malvaceae): An Interspecific Hybrid between Pavonia lasiopetala and Pavonia missionum}

\author{
Yongjun Yue \\ Department of Horticulture, University of Georgia, Athens, GA 30602
}

\begin{abstract}
John M. Ruter
Department of Horticulture, University of Georgia, Athens, GA 30602; and Institute of Plant Breeding, Genetics and Genomics
\end{abstract}

Additional index words. fertility, flower color, genome size, interspecific hybridization, ornamental, plant breeding

The genus Pavonia is one of the most abundant genera (more than 200 species) in the Malvaceae, and most of the species are native to North and South America (Fryxell, 1999). Although numerous species exist, only a few have been used as ornamental plants, such as $P$. hastata in Australia (Mitchell, 1982) and P. lasiopetala in Texas (Nokes, 1986). Pavonia lasiopetala is a small shrub native to Texas and northern Mexico, inhabiting dry, rocky landscapes (Fig. 1A). Pavonia missionum is a perennial shrub native to South America in Brazil, Argentina, and Paraguay (Fryxell, 1999) (Fig. 1B). Pavonia lasiopetala is native to central Texas; thus, plants can survive in U.S. Department of Agriculture (USDA) hardiness zone $7 \mathrm{~b}$ (U.S. Department of Agriculture-Agricultural Research Service, 2012). Pavonia missionum has been observed to reseed and come back every year (John Ruter, personal observation) at Tifton, GA [USDA hardiness zone $8 \mathrm{~b}$ (U.S. Department of Agriculture-Agricultural Research Service, 2012)].

Pavonia missionum belongs in subgen. Pavonia, sect. Pavonia, subsect. Hastifoliae, whereas $P$. lasiopetala is in subgen. Pavonia, sect. Pavonia, subsect. Exsertae (Fryxell, 1999). The base chromosome number for the genus Pavonia is $n=7$. Pavonia missionum is an octoploid $(2 n=8 x=56)$, whereas the chromosome number for $P$. lasiopetala is unknown (Fryxell, 1999). Both species prefer full sun to partial shade. The leaf bases are usually cordate with dentate margins for $P$. lasiopetala and cordate with crenate to serrate margins for $P$. missionum, and the apexes are acute for both species. The leaf blades are ovate to ovate-triangular with occasionally

Received for publication 30 Jan. 2021. Accepted for publication 18 Mar. 2021.

Published online 5 May 2021.

We thank Vickie Waters for her assistance with this research.

J.M.R. is the corresponding author. E-mail: ruter@ uga.edu.

This is an open access article distributed under the CC BY-NC-ND license (https://creativecommons. org/licenses/by-nc-nd/4.0/). three to five lobes (no lobe for $P$. lasiopetala) (Fryxell, 1999). The leaf of $P$. lasiopetala is moderate to heavily stellate pubescent (Fig. $2 \mathrm{~A}$ and $\mathrm{B}$ ). The adaxial leaf surface of $P$. missionum is heavily glandular-pubescent with appressed hairs, and the lower side of the leaf is sparsely pubescent with stellate and simple hairs (Fig. 2C and D). Both species have solitary flowers with staminal columns and five petals. Pavonia lasiopetala has five pink petnum has five separate orange-red petals. The two species can be used as ornamental plants as a result of their heat and drought tolerance, and their attraction of pollinators (Quinn and Klym, 2009). A new interspecific hybrid with reduced fertility, which carries the two species' desired ornamental traits, would be ideal for developing new cultivars. Thus, the interspecific hybrid $P . \times$ rufula was developed by crossing P. lasiopetala ( $(+)$ and $P$. missionum (ङ). Pavonia $\times$ rufula is an attractive perennial shrub with red or red-purple flowers and reduced fertility.

\section{Origin}

In Fall 2017, controlled crosses were made at the University of Georgia (UGA) Trial Garden in Athens, GA. In Spring 2018, 83 seeds from 60 initial crosses were treated with $15 \mathrm{~min}$ of acid scarification and were sown at the UGA Durham Horticulture Farm in 1020 trays $(54 \times 27 \times 6 \mathrm{~cm})$ (Landmark Plastic, Akron, $\mathrm{OH})$ in Watkinsville, GA. In Summer 2018, 26 germinated plants were transplanted to 2.8 -L pots at the UGA Durham Horticulture Farm. Only six of these seedlings showed novel traits, whereas the remaining seedlings appeared identical to the maternal parent. The six hybrid seedlings are intermediate morphologically to both parents. Five plants showed red [Royal Horticultural Society (RHS) 46B] flower color and one showed red-purple (RHS 57C) flower color (Royal Horticultural Society, 2001).

Terminal cuttings were collected on 5 Sept. 2018 for propagation, treated with indole-3-butyric acid potassium salt (Sigma-Aldrich Co., St. Louis, MO) at 3000 ppm for a als that slightly overlap, whereas $P$. missio- 5-s quick dip at the Durham Horticulture Research Farm. Cuttings were placed in $8.8 \times$ 8.8 -cm plastic pots (Kord; The HC Companies, Inc., Twinsburg, OH) with a substrate of Pro PRO-MIX BX MYCORRHIZAE Pro (PRO-MIX, Quakertown, PA) and Aero-soil perlite (Dicalite, Bala Cynwyd, PA) (1:1, v:v). Mist was applied (8 $\mathrm{s}$ every $5 \mathrm{~min}$ from 7:00 AM to 7:00 PM) for 2 weeks. Rooting was $100 \%$ for all cuttings attempted. The six crosses were overwintered at the Durham Horticulture Research Farm in an overwinter house (set temperature, $7^{\circ} \mathrm{C}$ ) in 2018-19 and were planted to the field on 2 May 2019 for further evaluation. Plants were spaced $1.22 \mathrm{~m}$ apart in a row, $1.83 \mathrm{~m}$ between rows, with drip irrigation (emitters $30.5 \mathrm{~cm}$ apart) applied twice a week. Fertilizer (10N-4.4P-8.3K; Athens Seed Company, Watkinsville, GA) was incorporated into the soil at a rate of $84 \mathrm{~kg}$ nitrogen/ha before planting.

To observe the difference of leaf hairs precisely, a scanning electron microscope experiment was conducted at the UGA Electron Microscopy Laboratory. Three leaves of both parents and the hybrid were cut with a circular hole punch (circle diameter, $0.85 \mathrm{~cm}$ ). Leaf samples (adaxial and abaxial) were coated using a Leica EM ACE600 Coater (Leica Microsystems Inc., Buffalo Grove, IL) and were then observed using an FE-SEM (Thermo Fisher Scientific, Precision, Waltham, MA).

Flow cytometry was used to determine the holoploid (2C) relative genome size for both species and the hybrid used in our research. The analysis was conducted at the UGA Center for Tropical and Emerging Global Diseases Cytometry Shared Resource Laboratory in Athens, GA, using a CytoFLEX Flow Cytometer (Beckman Coulter Life Sciences, Indianapolis, IN). Ten single leaf samples were collected and analyzed from each plant. Each leaf sample and internal standard of known genome size were included [Pisum sativum 'Ctirad' $(2 \mathrm{C}=9.19$ pg)]. About $1 \mathrm{~cm}^{2}$ of newly emerged leaf tissue from each plant was chopped using a razor blade into 1 - to $2-\mathrm{mm}^{2}$ pieces. The leaf pieces were then mixed with $400 \mu \mathrm{L}$ nuclei extraction buffer (CyStain ultraviolet Precise P; Sysmex Partec, Görlitz, Germany) for 30 s. Chopped particles were removed using 40$\mu \mathrm{m}$ mesh filters (nonsterile CellTrics filters; Sysmex America, Inc., Mundelein, IL), and $1600 \mu \mathrm{L}$ of nuclei staining buffer [CyStain Ultraviolet Precise P (4',6-diamidino-2-phenylindole), Sysmex Partec] was added. The holoploid (2C) genome size was calculated as $2 \mathrm{C}=[$ DNA content of the standard $\times($ Mean fluorescence of sample $\div$ Mean fluorescence of the sample)]. Means $\pm \operatorname{SE}(\mathrm{n}=10)$ are presented.

\section{Description}

The description of the new interspecific hybrid species is as follows: Pavonia $\times$ rufula Yue and Ruter [P. lasiopetala ( $(+)$ Scheele $\times$ P. missionum ( $\left.\sigma^{(}\right)$Eckman] is an interspecific hybrid with intermediate or different morphological characteristics compared with the 


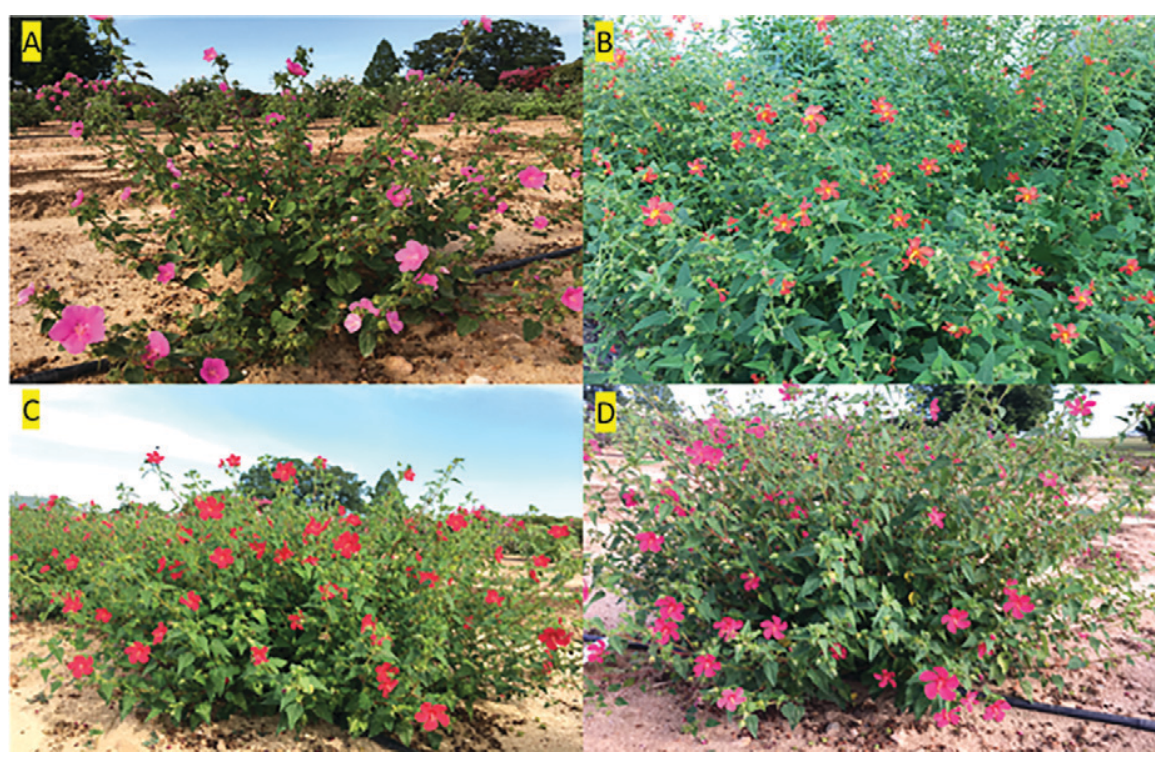

Fig. 1. Parents and new hybrids in the field at the UGA Durham Horticulture Farm. (A) Pavonia lasiopetala. (B) Pavonia missionum. (C) Pavonia $\times$ rufula (red). (D) Pavonia $\times$ rufula (red-purple).

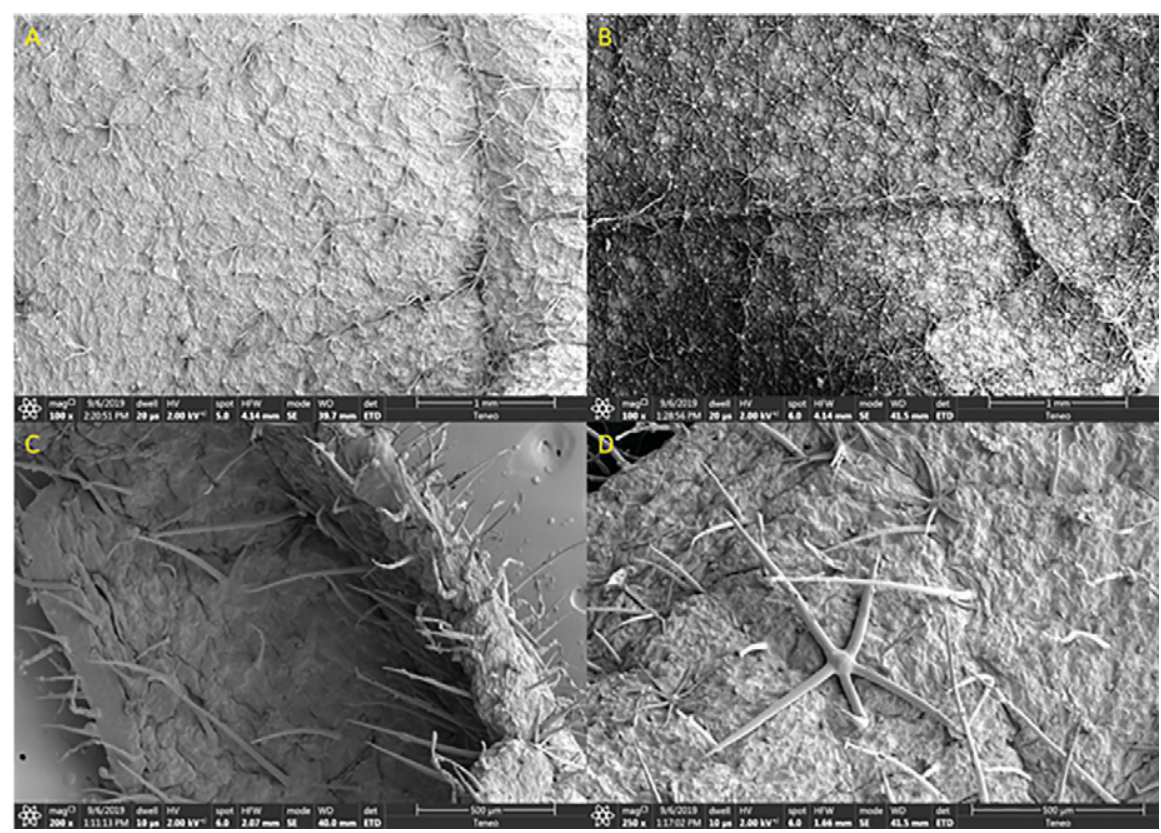

Fig. 2. Leaf surface and pubescence viewed using a scanning electron microscope for (A) Pavonia lasiopetala, upper leaf surface; (B) P. lasiopetala, lower leaf surface; (C) P. missionum, upper leaf surface; and (D) P. missionum, lower leaf surface.

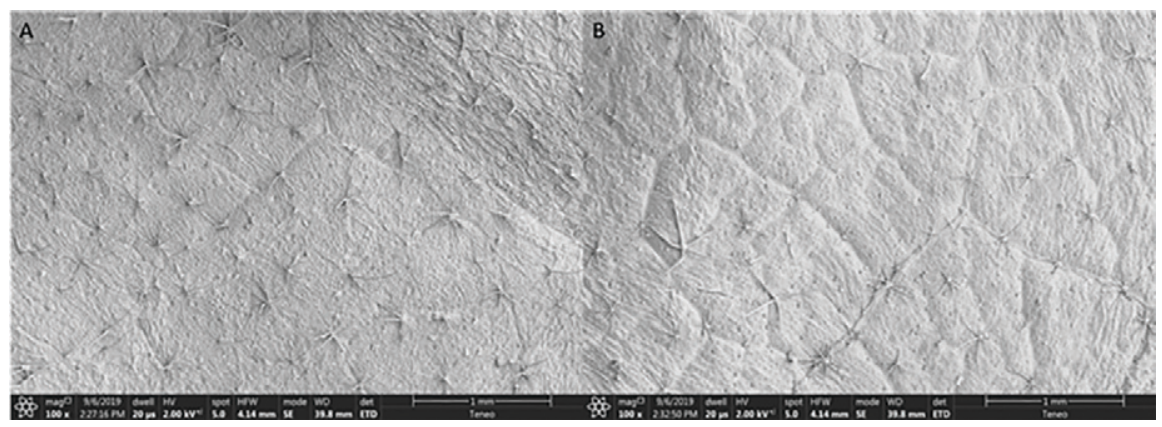

Fig. 3. Leaf surface and pubescence viewed using a scanning electron microscope for (A) $P$. $\times$ rufula, upper leaf surface; and (B) $P$. ×rufula, lower leaf surface. parents. The new hybrid's plant height is taller than either parent, the leaf area per leaf is less, the epicalyx lobes are intermediate to both parents, and the leaf shape and marginal serrations are similar to the paternal parent. The parent species' petal color is pink and orange-red, respectively, with the hybrid's petals being red to red-purple. The hybrid exhibits limited fertility.

The plants are small perennial shrubs with unique axillary red or red-purple flowers and five petals. The mericarps are reticulate-rugose, the adaxial leaf surfaces have simple trichomes on the lamina and stellate trichomes on prominent veins, and the abaxial surfaces have glandular and nonglandular simple trichomes. The leaf blades are usually 4 to $6 \mathrm{~cm}$ long and are slightly longer than wide, with an acute apex. The leaves have a cordate leaf base, dentate to crenate margins, and an overall cordate leaf shape. The leaf's upper surface is moderately stellate pubescent, and the lower surface is minutely stellate pubescent (Fig. 3). Petioles are green (RHS 144B) and mainly 2 to $3 \mathrm{~cm}$ long and 0.6 to $1.2 \mathrm{~mm}$ in diameter, with shorter simple hairs with glandular and nonglandular pubescence. Flowers are solitary and asymmetric, and are located in the leaf axis with 1 - to $2.5-\mathrm{cm}$-long pedicels and five lanceolate involucellar bracts $(7-9 \times$ 2-2.5 mm). Pavonia $\times$ rufula has five separate red petals with a staminal column in the center. Flowers measure 35 to $45 \mathrm{~mm}$ in diameter, with 10 pistils and about 23 to 36 stamens. Styles are $\approx 1.75 \mathrm{~cm}$ long and 0.1 to $0.2 \mathrm{~cm}$ in width, with a light red color (RHS 49A) at the base, whereas the stigmas are a deeper red (RHS 46A). Styles exceed the column, and stigmas are usually villous. Stamens are white (RHS 155B), with yellow (RHS 16A) pollen in the anther. Pedicels are green (RHS 144C) and measure 1.5 to $4 \mathrm{~cm}$ in length, with simple and stellate pubescence. There are five sepals at the bottom of each flower $\approx 1.3 \mathrm{~cm}$ in length. The sepals are lanceolate in shape, hirsute with simple and stellate pubescence, and light green (RHS 44D) with deeper green veins. There are also five lanceolate epicalyces split into one-seeded mericarps. The mericarps of $P$. $\times$ rufula are very similar to $P$. missionum, except the number of mericarps per fruit is reduced. Pavonia $\times$ rufula is larger compared with both parents (Table $1)$. The leaf area of $P$. $\times$ rufula is smaller than both parents, and the leaf shape is more like $P$. missionum (Table 1, Fig. 4). The other traits, such as style length, calyx lobe length, epicalyx lobe length, and mericarp shape, are similar to one parent or intermediate between two parents (Table 1). Pavonia $\times$ rufula is a perennial shrub with a woody base that prefers full sun to partial shade and blooms during the long days of summer in Athens, GA (USDA hardiness zone 8a; Fig. 1C and D) (U.S. Department of Agriculture-Agricultural Research Service, 2012).

Although $P . \times$ rufula is larger at maturity than either parent, the flower diameter shows 
Table 1. Morphological characteristics of Pavonia lasiopetala, P. missionum, and P. ×rufula.

\begin{tabular}{|c|c|c|c|}
\hline Characteristics & P. lasiopetala & P. missionum & P. $\times$ rufula \\
\hline Plant height $(\mathrm{cm})$ & $78.97 \mathrm{~b}^{\mathrm{z}}$ & $72.77 \mathrm{~b}$ & $97.57 \mathrm{a}$ \\
\hline Leaf area $\left(\mathrm{cm}^{2}\right)^{\mathrm{x}}$ & $15.99 \mathrm{a}$ & $15.59 \mathrm{a}$ & $12.63 \mathrm{~b}$ \\
\hline Sepal length $(\mathrm{cm})$ & $1.28 \mathrm{~b}$ & $1.34 \mathrm{a}$ & $1.34 \mathrm{a}$ \\
\hline Epicalyx lobe length $(\mathrm{cm})$ & $1.11 \mathrm{a}$ & $0.93 \mathrm{c}$ & $1.01 \mathrm{~b}$ \\
\hline Style length $(\mathrm{cm})$ & $1.72 \mathrm{a}$ & $1.71 \mathrm{a}$ & $1.75 \mathrm{a}$ \\
\hline Flower color & Pink (RHS 68A) & Orange-red (RHS 33A) & $\begin{array}{l}\text { Red (RHS 46B) or red-purple (RHS } \\
57 \mathrm{C} \text { ) }\end{array}$ \\
\hline Abaxial pubescence & $\begin{array}{l}\text { Stellate hairs, lamina, and veins } \\
\text { nonglandular }\end{array}$ & $\begin{array}{l}\text { Different-length hairs on lamina and } \\
\text { veins, veins simple and stellate }\end{array}$ & $\begin{array}{l}\text { Simple hairs sparse on lamina, } \\
\text { stellate hairs on veins }\end{array}$ \\
\hline Adaxial pubescence & $\begin{array}{l}\text { Some stellate hairs on lamina and } \\
\text { veins }\end{array}$ & Short hairs mainly on veins & $\begin{array}{l}\text { Multilength single and stellate hairs, } \\
\text { mainly on veins }\end{array}$ \\
\hline Petiole pubescence & $\begin{array}{l}\text { Pubescent nonglandular, many } \\
\text { stellates with } 3-7 \text { hairs }\end{array}$ & Long and short glandular hairs & $\begin{array}{l}\text { Shorter simple hairs with glandular } \\
\text { and nonglandular pubescence }\end{array}$ \\
\hline
\end{tabular}

${ }^{\mathrm{z}}$ Means followed by a different letter in the same row are significantly different $(P<0.05)$.

${ }^{\mathrm{y}}$ Plant width index: (East-west width + North-south width)/2.

${ }^{\mathrm{x}}$ Leaf area was recorded using a Li-3100C leaf area meter (LI-COR Biosciences, Lincoln, NE) on fully expanded leaves for five leaves per plant.

RHS $=$ Royal Horticultural Society.

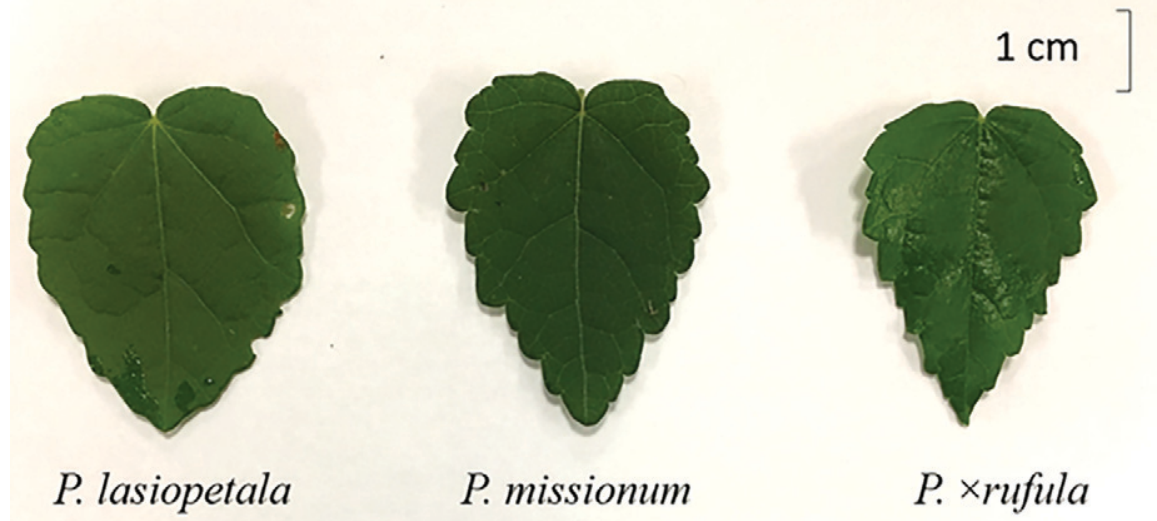

Fig. 4. Leaf shape of Pavonia lasiopetala, P. missionum, and P. $\times$ rufula.

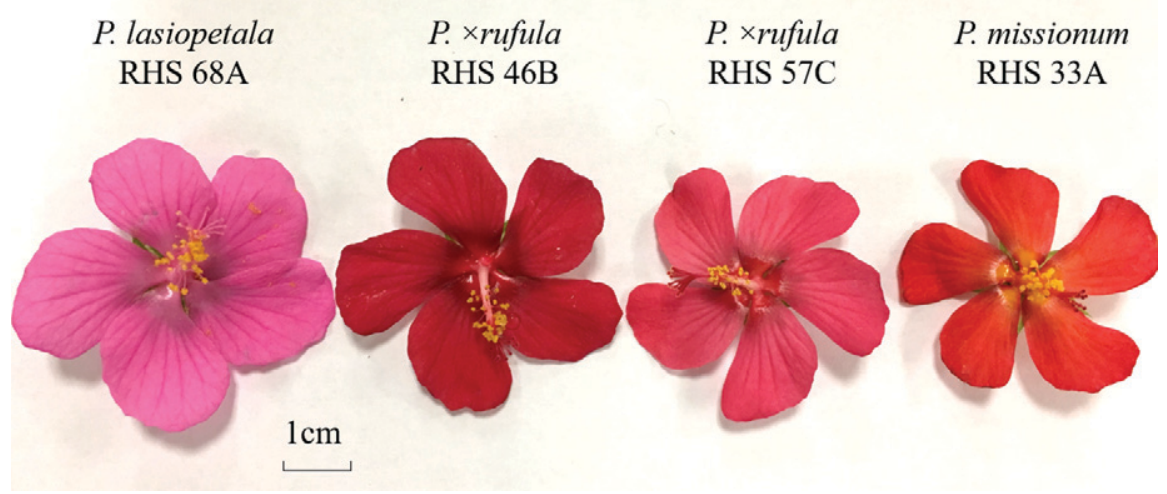

Fig. 5. Flower color of Pavonia lasiopetala, P. ×rufula, and P. missionum. RHS, Royal Horticultural Society.

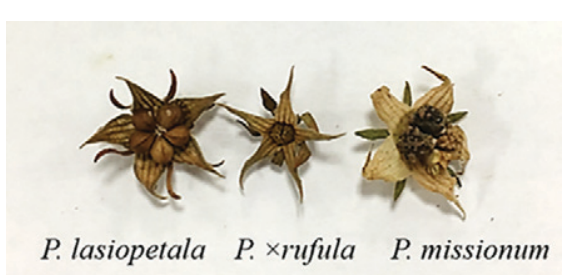

Fig. 6. Seed production of Pavonia lasiopetala, $P$. $\times$ rufula, and $P$. missionum. Normal-size mericarps formed on P. lasiopetala and P. missionum. Mericarps on $P$. $\times$ rufula were malformed and died at an early stage of development. no difference from the parents (Table 1, Fig. 5). The fertility of $P$. $\times$ rufula is reduced compared with both parents (Fig. 5). Previous research studies with other plants in the Malvaceae (Hibiscus sect. Furcaria) indicated that many interspecific hybrids were sterile or nearly so (Menzel et al., 1983). Partial or complete sterility is common in interspecific hybrids and is often caused by imperfect pairing of the chromosomes at meiosis (Fehr, 1991). Observations in 2018 of 100 flowers showed no seed was formed for all six P. $\times$ rufula seedling selections, and all the flowers aborted a few days after pollination (Fig. 6). In 2019, P. ×rufula plants at the UGA Durham Horticulture Farm produced a few seeds. If the seed was produced, only one viable seed was found in an individual fruit. Seeds were collected and sown in the UGA Horticulture Farm greenhouse for further evaluation. The resulting plants were uniform in appearance and had a phenotype like the hybrid parent.

The holoploid (2C) genome size for plants in this study were $P$. lasiopetala $(5.55 \pm 0.09$ pg), P. missionum (4.00 $\pm 0.09 \mathrm{pg})$, and $P$. $\times$ rufula $(4.76 \pm 0.03 \mathrm{pg})$. The intermediate genome size of the proposed new species provides further evidence for the hybrid nature of $P$. $\times$ rufula and suggests interploid hybridization. Although two hexadecaploid $(2 n=$ $16 x=112)$ species are known in the genus Pavonia, there is no known intermediate ploidy series between $8 x$ and 16x (Fryxell, 1999). Because there are no chromosome counts for P. lasiopetala or the entire subgen. Pavonia, sect. Pavonia, subsect. Exsertae, further research and chromosome count data may show $P$. lasiopetala and $P . \times$ rufula to have ploidy levels greater than $2 n=8 x$. Because no data for genome size exist for Pavonia in the Plant DNA C-values Database (2021), the values presented represent the first published holoploid (2C) genome sizes for this genus.

Controlled crosses between $P$. lasiopetala and $P$. missionum resulted in new interspecific hybrid seedlings with attractive red to redpurple flowers. Pavonia ×rufula Yue and Ruter (red rose mallow) is presented as a proposed name for this cross's hybrids and is validated with an appropriate diagnosis. Holotype: container-grown plant; UGA Durham Horticulture Farm, Watkinsville, GA; 24 Aug. 2018; Yue and Ruter 287572 (GA).

\section{Availability}

Information about the research and use of P. $\times$ rufula can be obtained from Dr. John Ruter (e-mail: ruter@uga.edu) from the College of Agricultural and Environmental 
Sciences, Department of Horticulture, University of Georgia, Athens, GA.

\section{Literature Cited}

Fehr, W.R. 1991. Principles of cultivar development. Vol. 1. Theory and technique. Macmillan, New York, NY.

Fryxell, P.A. 1999. Pavonia cavanilles (Malvaceae). The New York Botanical Garden Press, Bronx, NY.
Menzel, M.Y., P.A. Fryxell, and F.D. Wilson. 1983. Relationships among new world species of Hibiscus section Furcaria (Malvaceae). Brittonia 35:204-221, doi: 10.2307/ 2806016.

Mitchell, A.S. 1982. Economic aspects of the Malvaceae in Australia. Econ. Bot. 36:313-322, doi: 10.1007/BF02858556.

Nokes, J. 1986. How to grow native plants of Texas and the Southwest. Texas Monthly Press, Austin, TX.
Plant DNA C-values Database. 2021. Kew Gardens, London, UK. 2 Mar. 2021. <https:// cvalues.science.kew.org $>$.

Quinn, M. and M. Klym. 2009. Butterfly watching. Texas Park and Wildlife, Austin, TX.

Royal Horticultural Society. 2001. RHS colour chart. Royal Horticultural Society, London, UK.

U.S. Department of Agriculture-Agricultural Research Service. 2012. Plant hardiness zone map. 16 Sept 2019. <https://planthardiness.ars.usda.gov/>. 